\title{
Can Analyst Coverage Reduce Stock Price Crash Risk?-Evidence from China
}

\author{
Dongye Huang \\ Department of Finance, College of Economics, Jinan University, Guangzhou, China \\ Email: huangdongye1993@163.com
}

How to cite this paper: Huang, D.Y. (2018) Can Analyst Coverage Reduce Stock Price Crash Risk?-Evidence from China. American Journal of Industrial and Business Management, 8, 912-929. https://doi.org/10.4236/ajibm.2018.84063

Received: March 27, 2018

Accepted: April 25, 2018

Published: April 28, 2018

Copyright $\odot 2018$ by author and Scientific Research Publishing Inc. This work is licensed under the Creative Commons Attribution International License (CC BY 4.0).

http://creativecommons.org/licenses/by/4.0/

\begin{abstract}
Utilizing the date from 2010 to 2016 in China stock market, this paper studies the relation between analyst coverage and stock price crash risk. The result shows that security analyst coverage increases the risk of stock crash. When further dividing the analysts into star analysts and non-star analysts, the research found that the star analyst coverage can decrease stock price crash risk, and non-star analyst coverage can increase the stock price crash risk. And with the rise of star analyst ratio, the stock price crash risk will be lower.
\end{abstract}

\section{Keywords}

Crash Risk, Analyst Coverage, Star Analyst

\section{Introduction}

As the information intermediaries, with the professional skill, security analysts deliver information to investors and reduce the information opaque between investors and managers, through their research, forecasts, ratings and other activities. Meanwhile, the profit forecast by analysts is also regarded as a reference for evaluating managers' operation, which can restrain the opportunism of managers, reduce the enterprise's earnings management activities ( $\mathrm{Yu} 2008$ [1]; Hong et al. 2014 [2]), and finally become a powerful external supervision mechanism.

China's capital market is still not perfect. The role of security analysts is controversial. Especially with the exposure of analyst scandal in recent years, such as graphene events, extortionate price of mustard, the objectivity and profession of securities analysts are being questioned.

However, in recent years, in order to regulate the behavior of securities analysts, the supervision department also issued many documents to constraint 
their behaviours in services specification, independence and other aspects of the behavior of securities analysts, such as "Securities Research Report Interim Provisions" and "Securities Investment Advisory Business Interim Provisions" in 2010, "Code for Practice of Securities Research Report" and "Code of Conduct for Securities Analysts" in 2012. With the strengthening in supervision, can China's securities analysts play the role of information intermediaries and external supervision better?

Crash in stock prices is an extreme case of low price efficiency. It will not only reduce the enthusiasm of investors, but also harm the healthy development of the capital market, which has attracted wide attention in academia and government. According to the information structure theory by Myers and Jin (2006) [3], on the premise of information opaque, managers have motive to withhold bad news, causing it to accumulate. Once the accumulation of bad news exceeds a threshold that the manager will tolerate, the accumulated bad news swarm into the investor and finally lead to a huge negative return, namely crash.

Can security analysts reduce the information opaque between investors and managers, restrain the opportunism of managers and reduce the accumulation of bad news? Based on this consideration, this article focuses on the relationship between analyst coverage and stock price crash risk, and estimates the differences impact of the star analysts and the non-star analysts.

The contribution of this paper can be divided into two aspects. Firstly, I updated the research time of the sample and investigated whether the behavior of the analyst changed in the new time sample compared to the research by $\mathrm{Xu}$ et al. (2013) [4]. Secondly, this paper examines the difference impact of the star analyst and the non-star analyst, and found that their impact on crash risk was completely on the contrary. That is, the coverage by star analysts will decrease the crash risk, but the coverage by non-star analysts will increase the crash risk. The results showed that improving analysts' professional skills and strengthening the constraints on analysts behavior are necessary.

The limitations of this paper: 1) according to the existing research, I find that the optimism bias is the key that explains the failure of analysts' information mediation role and external supervision role. Many of the researches show that the analysts may succumb to investment banking, brokerage or institution investor and release an optimistic report. The paper does not further distinguish the differences between these kinds of different conflicts of interest. 2) There is no further study of the differences between star analysts and non-star analysts when they face the conflict of interest.

The paper includes five parts. Part one is the introduction of this paper, including the background introduction, the contribution and the limitation of this paper. Part two is the literature review and research hypothesis. I summarize the literature about crash risk and analysts. Part three includes the sample development, variable measurement, and research design. Part four is the empirical results of our paper. And part five is the conclusion. 


\section{Literature Review and Research Hypothesis}

\subsection{Literature Review}

\subsubsection{Crash Risk}

Since Jim \& Myers (2006) [3] proposed the information structure theory, a large number of scholars studied the stock price crash based on information opaque and agency problem. Nowadays, one of a common understanding about stock crash is that on the premise of incomplete information transparency, managers have the chance to catch cash flow (Hutton et al. 2009 [5]), absorb some of the firm-specify information and reduce the efficiency of stock market. Based on the consideration of managers' own career concern (Kothari et al. 2009 [6]) and equity incentive (Kim et al. 2011 [7]; Messrs Benmelech et al. 2010 [8]), managers have the motive to temporarily hide the bad news. But the tolerate of managers is limited, once pass the threshold, the accumulated bad news poured out to the stock market at a time, leading to large negative return and stock price crash. Therefore, it's effective to decrease crash risk by improving corporate governance, reducing the degree of information opaque and constraint managers' opportunism behaviors. Current studies found that it's effective to constrain the behavior of withhold bad news and decrease crash risk by improving accounting conservatism (Kim and Zhang 2010 [9]), strengthening the protection of investor (Wang Huacheng 2014 [10]), and enhancing the supervision by big shareholder (Wang Huacheng et al. 2015 [11]), audit (Wan Dongcan 2015 [12]), and institutional investors (An \& Zhang, 2013 [13]).

\subsubsection{Security Analysts}

Theoretically, as a professional, security analysts are able to take advantage of the public and private information their owned, make prediction and evaluation in their report independent and objective, which reduce the information asymmetry between the investors and managers, improve the pricing efficiency of stock price. The research of Barth and Hutton (2000) [14] shows that the coverage by analysts accelerates absorption the information in accrual and cash flow by stock price. At the same time, analysts' forecasting activities may be use as a reference to judge managers' activities by shareholders and the board of directors, and finally restrain the opportunistic behavior of managers. The study by Matsunaga and Park (2001) [15] show that managers may force a pay cuts if the company's performance cannot meet analysts' forecasts. Also, the market will punish the managers by falling in stock prices (Jensen 2010 [16]). Therefore, the coverage by analysts can play the role of external governance and reduce the managers' opportunism behaviors and earnings management activities (Yu 2008 [1]; Hong et al. 2014 [2]).

However, the impact of security analysts depends on the financial development. The study by Degeorge et al. (2003) [17] shows that only in the country with high financial development, can analyst coverage significantly reduce earnings management. China's capital market and financial development are rela- 
tively immature, the role of analysts is not clear. The study by Li Chuntao et al. (2016) [18] show that although the coverage by analysts reduce the accrual earning management and limited managers' opportunism, it also increase the real earnings management which is more coverter. The study by $\mathrm{Xu}$ et al. (2013) [19] show that the coverage by analysts increase the synchronous which means less efficiency and less firm-specific information. Meanwhile, the forecast by analysts tend to be systematic optimistic (Wu Yanran et al. 2012 [20]). Firstly, security analysts tend to overreact to good news and underreact to bad news. Secondly, they may be induced by the conflict of interest, which means the loss in independence and objective, and release optimistic forecasts and ratings. The study by Pan Yue et al. (2011) [21] show that firms with poor aftermarket performance are given more favorable biased report, especially by analysts affiliated with investment bank. The study by Zhao Liangyu et al. (2013) [22] show that in order to obtain the private information, the analyst will cooperate with the company's managers to issue an optimistic forecast when listed-companies public increasing shares, the rights issue, and big shareholder decreasing shareholding.

The impact of analysts to crash risk is also unclear. On the one hand, the existing studies have found that analysts' optimism bias exacerbated the accumulation of bad news, and eventually increase the stock price crash risk (Xu Nianhang et al. 2012 [23]). The study by Xu et al. (2013) [4] also found that analyst coverage may lead to high crash risk, but only the optimistic analyst coverage significantly increase crash risk. On the other hand, analyst coverage may improve stock market efficiency. The study by Pan Yue (2011) [24] found that analyst coverage can reduce the information opaque, thus with the increase in coverage, the positive relation between information opaque and crash risk may weaken.

\subsection{Research Hypothesis}

\subsubsection{Analyst Coverage and Crash Risk}

According to the existing study, security analysts may influence crash risk through two opposite paths. On the one hand, security analysts may be a powerful external supervision, constraint managers' opportunism, improve the information transparency and reduce the information asymmetry between investors and managers, thus reduce the accumulation of bad news and lower stock price crash risk. On the other hands, the loss in independence and objective, which cause the systematic optimistic deviation, lower the stock price efficiency and the supervision of security analysts. Much worse, it encourages the further accumulation of bad news which following by higher crash risk.

Therefore, two competitive hypotheses are putted forward:

H1a: If the analyst is mainly reflected as an effective external supervisory, analyst coverage is negative correlated with the crash risk.

$\mathrm{H} 1 \mathrm{~b}$ : If the optimistic system bias plays the major role, analyst coverage is positive correlated with the crash risk. 


\subsubsection{Star Analyst Coverage, Non-Star Analyst Coverage and Crash Risk}

According to the existing study, the accuracy of analyst forecast and the objective and independence of security analysts are the important factors that determine the role the analysts play.

With the decrease in forecast accuracy, analysts not only failed to reduce the information asymmetry of the market, may send the wrong message to the investors and the board of directors, which lead wrong action. Compared with the non-star analysts, firstly, the star analysts are more professional, and can better interpret the information (Xiao Hong and Li Shaoxuan 2017 [25]), their prediction and rating has more information and accuracy (Li Yong 2015 [26]), with lower positive deviation ( $\mathrm{Wu}$ Chaopeng 2013 [27]). Also, the star analysts are more risk averse, tend to striving for perfection predict not novelty (Zhang Zongxin and Yao Peiyi 2018 [28]). Thus, the forecast by star analysts may be a better reference for shareholders and directors to judge managers' behavior. Secondly, once their misconduct is founded by the investor, they may pay for a huge loss in reputation. Thus the star analysts may be more independent and objective. Also they activity may be more restrictive by the supervision department (Lin Jin et al. 2017 [29]). This paper believes that the supervisory role of star analysts may more powerful than non-star analysts, so that the coverage of star analysts can effectively reduce the crash risk. In order to estimate the differences between star analysts and non-star analysts, firstly, analyst coverage may be divided into star analyst coverage and non-star analyst coverage. And secondly, the ratio of star analyst coverage may be used to estimate whether with the rise of star analyst ratio, the crash risk may decrease. The hypotheses are putted forward:

$\mathrm{H}$ 2: Star analysts are negative correlated with stock price crashes.

$\mathrm{H} 3$ : With the rise of star analyst ratio, crash risk tends to be lower.

\section{Sample Development, Variable Measurement, and Research Design}

This paper selects the data from 2010 to 2016 in China stock market. The data of institutional investor are from RESSET database, the data of star analyst collect from New Fortune magazine and the other data are from CSMAR database. There are two reasons I choose 2010 for the start year of the sample. 1) Margin trading start implementing in China since 2010, which mean the start of selling mechanism in China. Recent research show that the implementing of margin trading may effectively alleviate the commercial motives of securities analysts, which means more accurate forecast [30] and lower optimistic deviation [31]. 2) The China Securities Regulatory Commission (CSRC) published "Securities Research Report Interim Provisions" and "Securities Investment Advisory Business Interim Provisions" in 2010 to constraint the business of security analyst, which mean the strengthen in supervision .Both may affect the role of securities analyst in the stock market. 
I exclude 1) financial service firm for their assets and liabilities structure is different from other industry; 2) firms with fewer than 30 of annual stock return date; 3) the ST stock; 4) listing year less than one year; 5) firm-year observations with insufficient financial data to calculate control variables. I am left with a final sample of 9925 firm-year observations. All the continuous variables in the model are winsored at the $1 \%$ level.

\subsection{Measuring Crash Risk}

The paper constructs two measures of crash risk following Kim et al. (2011) [7]. Firstly, estimate firm-specific weekly returns, denoted by $W$, as the natural log of one plus the residual return from the expanded market model regression for each firm and year:

$$
R_{i, t}=\alpha+\beta_{1} R_{m \cdot t-2}+\beta_{2} R_{m \cdot t-1}+\beta_{3} R_{m . t}+\beta_{4} R_{m \cdot t+1}+\beta_{5} R_{m \cdot t+2}+\varepsilon_{i, t}
$$

where $R_{i, t}$ is the return on stock $i$ in week $t$ and $R_{m . t}$ is the value-weighted A-share market return in week $t$. The firm-specific weekly return for firm $i$ in week $t$ are represented by $W_{i, t}=\ln \left(1+\varepsilon_{i, t}\right)$, where $\varepsilon_{i, t}$ is the residual in Equation (1):

The first measure of crash risk is the negative coefficient of skewness, NCSKEW, see Equation (2)

$$
N S C K E W_{i, t}=-\frac{\left[n(n-1)^{\frac{3}{2}} \sum W_{i, t}^{2}\right]}{\left[(n-1)(n-2)\left(\sum W_{i, t}^{2}\right)^{\frac{3}{2}}\right]}
$$

where $n$ is the number of observations of firm-specific weekly returns of firm $i$ during year $t$. With the growth of $N S C K E W$, the firm experience high crash risk

The second measure of crash risk is down-to-up volatility, DUVOL, which is computed as Equation (3).

$$
D_{U V O L}=\log \left\{\frac{\left[\left(n_{u}-1\right) \sum_{D O W N} W_{i, t}^{2}\right]}{\left[\left(n_{d}-1\right) \sum_{U P} W_{i, t}^{2}\right]}\right\}
$$

where $n_{u}$ and $n_{d}$ are the numbers of up and down weeks. Also with the growth of $D U V O L$, the firm experience high crash risk

\subsection{Measuring Analyst Coverage}

Analyst coverage is measured as the number of analysts, denoted Coverage. And then, I divide analyst coverage into star analyst coverage and non-star analyst coverage. I consider the coverage of an analyst selected by New Fortune magazine as the best analyst in year $t-1$ as star analyst coverage (Star) since year $t$. The difference between the number of analysts and the number of star analysts is the number of non-star analysts (nonStar).

Furthermore, I use the ratio between the number of star analysts and the number of all analysts, denoted Ratio, to estimate whether the relative changes of 
star analysts will decrease crash risk.

$$
\text { Ratio }_{i, t}=\frac{\text { Star }_{i, t}}{\text { Coverage }_{i, t}}
$$

\subsection{Control Variables}

The paper includes a set of control variables deemed to be potential predictors of crash risk. The lagged NCSKEW variable is the negative skewness of past firm-specific stock returns. The variable $R E T$ is the mean of firm-specific weekly returns over the fiscal-year period. The variable $S I G M A$ is the standard deviation of firm-specific weekly returns over the year. The variable $L E V$ is the ratio between liabilities and assets. The variable $B M$ is the book value of equity divided by the market value of equity. The variables SIZE is defined as the logarithm of total assets. The variable DTURN is detrended stock trading volume, which is a proxy for investor heterogeneity. The variables $R O A$ is defined as the income before extraordinary items divided by total assets. The variables Inshold is the shareholding by institution investor. The Top 10 is the shareholding of top 10 shareholder. The variables Opaque is a proxy for information transparency, which is defined as discretionary accruals as estimated from the modified Jones model (Dechow et al., 1995) [32]. We also include industry and year dummies to control for industry and year fixed effects. Detailed variable definitions are given in Appendix A.

\subsection{Empirical Models}

\subsubsection{Analyst Coverage and Crash Risk}

To estimate the impact of analyst coverage on stock price crash risk, the following regression equation is used.

$$
\text { Crash }_{i, t+1}=\alpha_{0}+\alpha_{1} \text { Coverage }_{i, t}+\sum_{k} \varphi_{k} \text { Control }_{i, t}^{k}+\varepsilon_{i, t+1}
$$

where Crash $_{i, t+1}$ is the crash risk in $t+1$ of firm $i$, which is represent by NCSKEW and DUVOL. Coverage ${ }_{i, t}$ is the number of analysts following firm $i$. The Control represents a series of control variables in Section 3.3. If $\alpha_{1}>0$, it supposes hypothesis H1a, which means the following of analysts decrease the crash risk. If $\alpha_{1}<0$, it supposes hypothesis H1b, which means the following of analysts increase the crash risk.

\subsubsection{Star Analyst Coverage, Non-Star Analyst Coverage and Crash Risk}

To test whether the impact by star analyst and non-star analyst are difference, Equation (6) is used.

$$
\operatorname{Crash}_{i, t+1}=\alpha_{0}+\alpha_{1} \text { Star }_{i, t}+\alpha_{2} \text { nonStar }_{i, t}+\sum_{k} \varphi_{k} \text { Control }_{i, t}^{k}+\varepsilon_{i, t+1}
$$

where Star $_{i, t}$ is the number of star analysts following firm $i$. nonStar $r_{i, t}$ is the difference between the number of analysts and the number of star analysts.

Furthermore, to test hypothesis $\mathrm{H} 3$, I estimate the regression equation

$$
\text { Crash }_{i, t+1}=\alpha_{0}+\alpha_{1} \text { Ratio }_{i, t}+\alpha_{2} \text { Coverage }_{i, t}+\sum_{k} \varphi_{k} \text { Control }_{i, t}^{k}+\varepsilon_{i, t+1}
$$


where Ratio $_{i, t}$ is the following of star analysts divided by the following of all analysts.

\section{Empirical Results}

\subsection{Descriptive Statistics}

Table 1 presents the sample's descriptive statistics. The mean value of NCSKEW and DUVOL is -0.324 and -0.210 . The standard deviation of NCSKEW and $D U V O L$ is 0.772 and 0.525 . The mean value of Coverage and Star is 7.961 and 1.905 , which means on average 7.961 analysts follow a firm in a given year and 1.905 star analysts follow a firm in a fiscal year. The mean value and standard deviation of Ratio is 0.189 and 0.229 . The mean value and standard deviation of $R E T$ is -0.001 and 0.002 . The mean value and standard deviation of SIGMA is 0.049 and 0.020 . The mean value and standard deviation of SIZE is 22.28 and 1.242. The mean value and standard deviation of DTRUN is -0.051 and 0.327 . The mean value and standard deviation of $M B$ is 2.024 and 1.732 . The mean value and standard deviation of Top 10 is 55.860 and 15.150 . The mean value and standard deviation of $R O A$ is 0.048 and 0.044 . The mean value and standard deviation of $L E V$ is 0.454 and 0.202 . The mean value and standard deviation of Inshold is 0.230 and 0.216 . The mean value and standard deviation of Opaque is 0.063 and 0.047 .

Table 1. Descriptive statistics. Present descriptive statistics for the sample in 2010-2016. Here Q1 and Q3 are first and third quartile values. All variables are as defined in Appendix A.

\begin{tabular}{|c|c|c|c|c|c|}
\hline Variable & Mean & Std. & Q1 & Median & Q3 \\
\hline$N C S K E W_{i, t+1}$ & -0.324 & 0.772 & -0.722 & -0.252 & 0.150 \\
\hline$D U V O L_{i, t+1}$ & -0.210 & 0.525 & -0.538 & -0.188 & 0.143 \\
\hline Coverage $_{i, t}$ & 7.961 & 8.837 & 1 & 5 & 12 \\
\hline Star $_{i, t}$ & 1.905 & 2.432 & 0 & 1 & 3 \\
\hline nonStar $_{i, t}$ & 6.061 & 6.980 & 1 & 4 & 9 \\
\hline Ratio $_{i, t}$ & 0.189 & 0.229 & 0 & 0.143 & 0.308 \\
\hline$R E T_{i, t}$ & -0.001 & 0.002 & -0.001 & -0.001 & 0 \\
\hline$S I G M A_{t, t}$ & 0.049 & 0.020 & 0.035 & 0.045 & 0.058 \\
\hline$S I Z E_{i, t}$ & 22.28 & 1.242 & 21.380 & 22.080 & 22.990 \\
\hline $\operatorname{DTURN}_{i, t}$ & -0.051 & 0.327 & -0.238 & -0.040 & 0.128 \\
\hline$M B_{i, t}$ & 2.024 & 1.732 & 0.814 & 1.519 & 2.643 \\
\hline Top $10_{i, t}$ & 55.860 & 15.150 & 44.760 & 56.330 & 66.820 \\
\hline$R O A_{t, t}$ & 0.048 & 0.044 & 0.025 & 0.043 & 0.068 \\
\hline$L E V_{i, t}$ & 0.454 & 0.202 & 0.297 & 0.455 & 0.615 \\
\hline Inshold $_{i, t}$ & 0.230 & 0.216 & 0.056 & 0.155 & 0.357 \\
\hline Opaque $_{i, t}$ & 0.063 & 0.047 & 0.031 & 0.049 & 0.080 \\
\hline
\end{tabular}




\subsection{Analyst Coverage and Crash Risk}

Table 2 presents the impact of analyst coverage on future stock price crash risk to test hypothesis H1. Colum (1) and (2) are estimated by OLS regression. The coefficient of analyst coverage is significant positive at $1 \%$ level, suggesting that with the raise of analyst coverage, the crash risk may increase. The finding support H1b, which mean that the supervision role of security analyst on average is weak. The paper also control the firm fixed effect in column (3) and (4) for robust test. The finding is not change.

\subsection{Star Analyst Coverage, Non-Star Analyst Coverage and Crash Risk}

Table 3 presents the difference impact of star analysts and non-star analysts to test hypothesis H2. Colum (1) and (2) are estimated by OLS regression. The finding show that star analyst coverage is significant negative with crash risk at $10 \%$ level, and non-star analyst coverage is significant positive with crash risk at $1 \%$ level, which mean that the star analysts may act as an external supervision and constrain the accumulation of bad news, and the not-star analysts increase the crash risk for their systematic optimistic deviation. There are two reasons can explain this difference. Firstly, compare to non-star analysts, star analysts are more professional, which means lower optimistic deviation and more specify-information in their forecast. Secondly, for avoiding huge loss in reputation, star analysts may be more independent and objective. The result also show that it's importance to enhance the profession of security analysts, and the reputation may be effective in restrain their misconduct. I also control the firm fixed effect in column (3) and (4) for robust. The finding is not change.

Table 4 shows the result of Equation (7), which used to test if the relative change of star analysts can impact the crash risk. Variable Ratio is defined as the number of star analysts divided by the number of all analysts in firm $i$. The result in Table 4 shows that the relative increase in star analysts will reduce the crash risk. The finding shows that the star analysts indeed act as an external supervision. I also control the firm fixed effect in column (3) and (4) for robust. The finding is not changed.

\subsection{Endogenous Concern}

\subsubsection{Analysts Coverage and Crash Risk}

Analyst coverage and crash risk may be endogenously determined. To solve the potential endogeneity problem, the paper follow Zhou et al. (2016) [33] and Yu (2008) [1], using the expected analyst coverage, denoted as exp_cov, as an instrumental variable to estimate the relation between analyst coverage and crash risk. To calculate the expected analyst coverage, firstly, use Equation (8) and Equation (9) to estimate the exp_cov

$$
\text { Expected Analysis }_{i, j, t}=\frac{\text { Brokersize }_{j, t}}{\text { Brokersize }_{j, t-1}} * \text { Analysis }_{i, j, t-1}
$$


Table 2. Impact of analyst coverage on future stock crash risk. Colum (1) and (2) are the result estimated by OLS regression, which control industry and year fixed effect. Colum (3) and (4) are the result controlled the firm fixed effect for robust. All variables are as defined in Appendix A. The standard errors are reported in parentheses. The superscripts ${ }^{*}{ }^{* *}$, and ${ }^{* * *}$ indicate statistical significance at the $10 \%, 5 \%$ and $1 \%$ levels, respectively.

\begin{tabular}{|c|c|c|c|c|}
\hline \multirow{2}{*}{ VARIABLES } & (1) & (2) & (3) & (4) \\
\hline & $N_{C S K E W_{i, t+1}}$ & $D U V O L_{i, t+1}$ & $N_{C S K E W_{i, t+1}}$ & $D U V O L_{i, t+1}$ \\
\hline \multirow[t]{2}{*}{ Constant } & $0.765^{\star * *}$ & $0.888^{\star * *}$ & $-1.617^{\star \star}$ & -0.731 \\
\hline & $(0.243)$ & $(0.164)$ & $(0.697)$ & $(0.475)$ \\
\hline \multirow[t]{2}{*}{ Coverage $_{i, t}$} & $0.009^{* * *}$ & $0.006^{* * *}$ & $0.005^{* * *}$ & $0.004^{* * *}$ \\
\hline & $(0.001)$ & $(0.001)$ & $(0.001)$ & $(0.001)$ \\
\hline \multirow[t]{2}{*}{$R E T_{i, t}$} & 2.838 & 3.115 & 3.620 & 6.747 \\
\hline & $(6.035)$ & (4.113) & $(6.724)$ & $(4.584)$ \\
\hline \multirow[t]{2}{*}{$S I G M A_{t, t}$} & $3.045^{* * *}$ & $1.639^{\star * *}$ & $3.248^{\star * *}$ & $1.743^{* * *}$ \\
\hline & $(0.616)$ & $(0.421)$ & $(0.774)$ & $(0.516)$ \\
\hline \multirow[t]{2}{*}{$\operatorname{DTURN}_{i, t}$} & -0.014 & 0.003 & -0.057 & -0.028 \\
\hline & $(0.033)$ & $(0.022)$ & $(0.036)$ & $(0.024)$ \\
\hline \multirow[t]{2}{*}{$S I Z E_{i, t}$} & $-0.056^{\star * *}$ & $-0.053^{\star * *}$ & 0.038 & 0.009 \\
\hline & $(0.011)$ & $(0.007)$ & $(0.033)$ & $(0.023)$ \\
\hline \multirow[t]{2}{*}{$M B_{i, t}$} & $0.016^{* *}$ & 0.007 & $0.051^{\star * *}$ & $0.040^{* * *}$ \\
\hline & $(0.008)$ & $(0.005)$ & $(0.012)$ & $(0.008)$ \\
\hline \multirow[t]{2}{*}{$N_{C S K E W_{i, t}}$} & $0.064^{* * *}$ & $0.046^{* * *}$ & $-0.138^{\star * *}$ & $-0.073^{\star * *}$ \\
\hline & $(0.013)$ & $(0.008)$ & $(0.014)$ & $(0.009)$ \\
\hline \multirow[t]{2}{*}{ Opaque $_{i, t}$} & $0.322^{\star}$ & 0.113 & 0.375 & 0.237 \\
\hline & $(0.178)$ & $(0.122)$ & $(0.287)$ & $(0.191)$ \\
\hline \multirow[t]{2}{*}{ Inshold $_{i, t}$} & $0.082^{\star}$ & 0.041 & 0.104 & 0.042 \\
\hline & $(0.042)$ & $(0.029)$ & $(0.074)$ & $(0.050)$ \\
\hline \multirow[t]{2}{*}{$L E V_{i, t}$} & -0.027 & -0.015 & -0.166 & -0.062 \\
\hline & $(0.056)$ & $(0.038)$ & $(0.121)$ & $(0.081)$ \\
\hline \multirow[t]{2}{*}{$R O A_{i, t}$} & 0.058 & -0.024 & -0.225 & -0.064 \\
\hline & $(0.218)$ & $(0.145)$ & $(0.304)$ & $(0.200)$ \\
\hline \multirow[t]{2}{*}{ Top10 $0_{i, t}$} & 0.001 & $0.001^{*}$ & $0.005^{\star * *}$ & $0.003^{* * *}$ \\
\hline & $(0.001)$ & $(0.000)$ & $(0.001)$ & $(0.001)$ \\
\hline Industry fixed effect & Control & Control & & \\
\hline Year fixed effect & Control & Control & Control & Control \\
\hline Firm fixed effect & & & Control & Control \\
\hline Observations & 9925 & 9925 & 9925 & 9925 \\
\hline R-squared & 0.060 & 0.061 & 0.059 & 0.053 \\
\hline
\end{tabular}

where Expected Analysis $s_{i, j, t}$ is the expected analysts in broker $j$ in firm $i$ on 
Table 3. The difference impact of star analyst coverage and non-star analyst coverage. Colum (1) and (2) are the result estimated by OLS regression, which control industry and year fixed effect. Colum (3) and (4) are the result controlled the firm fixed effect for robust. All variables are as defined in Appendix A. The standard errors are reported in parentheses. The superscripts ${ }^{*}{ }^{* *}$, and ${ }^{* * *}$ indicate statistical significance at the $10 \%, 5 \%$ and $1 \%$ levels, respectively.

\begin{tabular}{|c|c|c|c|c|}
\hline \multirow{2}{*}{ VARIABLES } & (1) & (2) & (3) & (4) \\
\hline & $N_{C S K E W_{i, t+1}}$ & $D U V O L_{i, t+1}$ & $N_{C S K E W_{i, t+1}}$ & $D U V O L_{i, t+1}$ \\
\hline \multirow[t]{2}{*}{ Constant } & $0.713^{* * *}$ & $0.846^{* * *}$ & $-1.861^{\star * *}$ & $-0.917^{\star}$ \\
\hline & $(0.245)$ & $(0.165)$ & $(0.700)$ & $(0.477)$ \\
\hline \multirow{2}{*}{ Star $_{i, t}$} & $-0.008^{\star}$ & $-0.007^{\star *}$ & $-0.015^{\star * *}$ & $-0.011^{* * *}$ \\
\hline & $(0.005)$ & $(0.003)$ & $(0.005)$ & $(0.004)$ \\
\hline \multirow[t]{2}{*}{ nonStar $_{i, t}$} & $0.014^{* * *}$ & $0.010^{* * *}$ & $0.011^{* * *}$ & $0.008^{* * *}$ \\
\hline & $(0.002)$ & $(0.001)$ & $(0.002)$ & $(0.002)$ \\
\hline \multirow[t]{2}{*}{$R E T_{i, t}$} & 3.097 & 3.325 & 3.973 & 7.007 \\
\hline & $(6.027)$ & $(4.105)$ & $(6.711)$ & $(4.571)$ \\
\hline \multirow[t]{2}{*}{$\operatorname{SIGMA}_{t, t}$} & $3.132^{* * *}$ & $1.709^{* * *}$ & $3.353^{* * *}$ & $1.823^{* * *}$ \\
\hline & $(0.615)$ & $(0.420)$ & $(0.773)$ & $(0.515)$ \\
\hline \multirow[t]{2}{*}{$D T U R N_{i, t}$} & -0.016 & 0.002 & $-0.060^{*}$ & -0.031 \\
\hline & $(0.033)$ & $(0.023)$ & $(0.036)$ & $(0.025)$ \\
\hline \multirow[t]{2}{*}{$S I Z E_{i, t}$} & $-0.054^{\star * *}$ & $-0.052^{\star * *}$ & 0.049 & 0.017 \\
\hline & $(0.011)$ & $(0.007)$ & $(0.033)$ & $(0.023)$ \\
\hline \multirow[t]{2}{*}{$M B_{i, t}$} & $0.015^{\star *}$ & 0.007 & $0.049^{* * *}$ & $0.038^{* * *}$ \\
\hline & $(0.008)$ & $(0.005)$ & $(0.012)$ & $(0.008)$ \\
\hline \multirow[t]{2}{*}{$N_{C S K E} W_{i, t}$} & $0.064^{* * *}$ & $0.047^{* * *}$ & $-0.137^{\star * *}$ & $-0.073^{* * *}$ \\
\hline & $(0.013)$ & $(0.008)$ & $(0.014)$ & $(0.009)$ \\
\hline \multirow[t]{2}{*}{ Opaque $_{i, t}$} & $0.330^{*}$ & 0.121 & 0.356 & 0.223 \\
\hline & $(0.178)$ & $(0.122)$ & $(0.286)$ & $(0.190)$ \\
\hline \multirow[t]{2}{*}{ Inshold $_{i, t}$} & $0.080^{*}$ & 0.039 & 0.107 & 0.044 \\
\hline & $(0.042)$ & $(0.028)$ & $(0.074)$ & $(0.050)$ \\
\hline \multirow[t]{2}{*}{$L E V_{i, t}$} & -0.024 & -0.0128 & -0.164 & -0.060 \\
\hline & $(0.056)$ & $(0.038)$ & $(0.120)$ & $(0.080)$ \\
\hline \multirow[t]{2}{*}{$R O A_{t, t}$} & 0.094 & 0.004 & -0.210 & -0.052 \\
\hline & $(0.218)$ & $(0.145)$ & $(0.304)$ & $(0.200)$ \\
\hline \multirow[t]{2}{*}{ Top $10_{i, t}$} & 0.001 & $0.001^{\star}$ & $0.004^{* * *}$ & $0.003^{* * *}$ \\
\hline & $(0.0017)$ & $(0.000)$ & $(0.001)$ & $(0.001)$ \\
\hline Industry fixed effect & Control & Control & & \\
\hline Year fixed effect & Control & Control & Control & Control \\
\hline Firm fixed effect & & & Control & Control \\
\hline Observations & 9925 & 9925 & 9925 & 9925 \\
\hline R-squared & 0.061 & 0.063 & 0.061 & 0.055 \\
\hline
\end{tabular}


Table 4. The impact of star analyst relative change in crash risk. Estimate whether the relative change of star analysts impact the crash risk. Colum (1) and (2) are the result estimated by OLS regression, which control industry and year fixed effect. Colum (3) and (4) are the result controlled the firm fixed effect for robust. All variables are as defined in Appendix A. The standard errors are reported in parentheses. The superscripts ${ }^{\star},{ }^{\star *}$, and ${ }^{* * *}$ indicate statistical significance at the $10 \%, 5 \%$ and $1 \%$ levels, respectively.

\begin{tabular}{|c|c|c|c|c|}
\hline \multirow{2}{*}{ VARIABLES } & (1) & (2) & (3) & (4) \\
\hline & NCSKEW $_{i, t+1}$ & $D U V O L_{i, t+1}$ & $N_{C S K E W_{i, t+1}}$ & $D U V O L_{i, t+1}$ \\
\hline \multirow[t]{2}{*}{ Constant } & $0.686^{\star *}$ & $0.919^{\star * *}$ & -1.133 & -0.849 \\
\hline & $(0.303)$ & $(0.203)$ & (1.019) & $(0.735)$ \\
\hline \multirow[t]{2}{*}{ Ratio $_{i, t}$} & $-0.163^{\star *}$ & $-0.104^{\star \star}$ & $-0.165^{\star}$ & $-0.115^{\star}$ \\
\hline & $(0.076)$ & $(0.052)$ & $(0.098)$ & $(0.067)$ \\
\hline \multirow[t]{2}{*}{ Coverage $_{i, t}$} & $0.006^{* * *}$ & $0.004^{\star * *}$ & 0.002 & 0.002 \\
\hline & $(0.002)$ & $(0.001)$ & $(0.002)$ & $(0.002)$ \\
\hline \multirow{2}{*}{$R E T_{i, t}$} & $13.790^{*}$ & $9.949^{*}$ & 7.567 & 10.580 \\
\hline & (7.948) & $(5.591)$ & $(10.110)$ & $(7.175)$ \\
\hline \multirow[t]{2}{*}{$S_{\text {SIGMA }}$} & $1.970^{* *}$ & $1.237^{* *}$ & $2.024^{*}$ & 1.204 \\
\hline & $(0.850)$ & $(0.576)$ & (1.183) & $(0.809)$ \\
\hline \multirow[t]{2}{*}{$D T U R N_{i, t}$} & -0.075 & -0.034 & -0.058 & -0.026 \\
\hline & $(0.047)$ & $(0.032)$ & $(0.055)$ & $(0.037)$ \\
\hline \multirow[t]{2}{*}{$S I Z E_{i, t}$} & $-0.043^{\star * *}$ & $-0.048^{* * *}$ & 0.025 & 0.019 \\
\hline & $(0.014)$ & $(0.009)$ & $(0.048)$ & $(0.035)$ \\
\hline \multirow{2}{*}{$M B_{i, t}$} & $0.028^{* * *}$ & $0.015^{\star *}$ & $0.046^{* * *}$ & $0.041^{* * *}$ \\
\hline & $(0.010)$ & $(0.006)$ & $(0.017)$ & $(0.012)$ \\
\hline \multirow[t]{2}{*}{$N_{C S K E} W_{i, t}$} & $0.056^{* * *}$ & $0.040^{\star * *}$ & $-0.169^{* * *}$ & $-0.096^{\star * *}$ \\
\hline & $(0.016)$ & $(0.011)$ & $(0.019)$ & $(0.013)$ \\
\hline \multirow[t]{2}{*}{ Opaque $_{i, t}$} & 0.085 & -0.091 & -0.152 & -0.217 \\
\hline & $(0.232)$ & $(0.157)$ & $(0.401)$ & $(0.277)$ \\
\hline \multirow{2}{*}{ Inshold $_{i, t}$} & 0.080 & 0.039 & $0.184^{*}$ & 0.054 \\
\hline & $(0.052)$ & $(0.035)$ & $(0.102)$ & $(0.071)$ \\
\hline \multirow[t]{2}{*}{$L E V_{i, t}$} & -0.066 & -0.036 & 0.120 & 0.016 \\
\hline & $(0.078)$ & $(0.052)$ & $(0.170)$ & $(0.122)$ \\
\hline \multirow[t]{2}{*}{$R O A_{t, t}$} & 0.094 & -0.034 & 0.238 & 0.064 \\
\hline & $(0.292)$ & $(0.199)$ & $(0.474)$ & $(0.331)$ \\
\hline \multirow[t]{2}{*}{ Top10 } & -0.001 & -0.000 & 0.002 & $0.003^{*}$ \\
\hline & $(0.001)$ & $(0.000)$ & $(0.002)$ & $(0.001)$ \\
\hline Industry fixed effect & Control & Control & & \\
\hline Year fixed effect & Control & Control & Control & Control \\
\hline Firm fixed effect & & & Control & Control \\
\hline Observations & 5356 & 5356 & 5356 & 5356 \\
\hline R-squared & 0.069 & 0.073 & 0.074 & 0.075 \\
\hline
\end{tabular}


year $t$. Brokersize $_{j, t}$ and Brokersize $e_{j, t-1}$ is a proxy of broker size in broker $j$ on year $t$, which is defined by the total number of analysts employed in broker $j$ on year $t$. Analysis i $_{i, t-1}$ is the analyst coverage for broker $j$ s coverage of firm $i$ on year $t-1$.

I use the 2 sls regression to estimate Equation (5), the result showing in Table 5. The result shows that the coefficients of Coverage is positive and significant in $1 \%$ level, supporting hypothesis H1b.

Table 5. Endogenous concern for the impact of analysts coverage and crash risk. The first column shows the first stage regression result, and the second and third column is the regression result in second stage. All variables are as defined in Appendix A. The standard errors are reported in parentheses. The superscripts ${ }^{\star},{ }^{* *}$, and ${ }^{\star * *}$ indicate statistical significance at the $10 \%, 5 \%$ and $1 \%$ levels, respectively.

\begin{tabular}{|c|c|c|c|}
\hline \multirow{2}{*}{ VARIABLES } & \multirow{2}{*}{$\begin{array}{l}\text { First stage } \\
\text { Coverage }_{i, t}\end{array}$} & \multicolumn{2}{|c|}{ Second stage } \\
\hline & & $N C S K E W_{i, t+1}$ & $D U V O L_{i, t+1}$ \\
\hline \multirow[t]{2}{*}{ Constant } & $-15.294^{\star * *}$ & $0.633^{\star \star}$ & $0.829^{* * *}$ \\
\hline & $(1.300)$ & $(0.254)$ & $(0.173)$ \\
\hline \multirow[t]{2}{*}{ exp_cov ${ }_{i, t}$} & $1.032^{\star * *}$ & & \\
\hline & $(0.009)$ & & \\
\hline \multirow[t]{2}{*}{ Coverage $_{i, t}$} & & $0.008^{\star * *}$ & $0.005^{\star * *}$ \\
\hline & & $(0.001)$ & $(0.001)$ \\
\hline \multirow[t]{2}{*}{$R E T_{i, t}$} & $-69.613^{\star *}$ & 2.880 & 3.133 \\
\hline & $(27.268)$ & $(6.028)$ & $(4.108)$ \\
\hline \multirow[t]{2}{*}{$S_{I G M A_{t, t}}$} & $38.455^{* * *}$ & $3.078^{* * *}$ & $1.654^{* * *}$ \\
\hline & $(2.984)$ & $(0.615)$ & $(0.420)$ \\
\hline \multirow[t]{2}{*}{$D T U R N_{i, t}$} & $-0.259^{*}$ & -0.013 & 0.004 \\
\hline & $(0.150)$ & $(0.033)$ & $(0.023)$ \\
\hline \multirow[t]{2}{*}{$\operatorname{SIZE}_{i, t}$} & $0.698^{\star * *}$ & $-0.049^{\star * \star}$ & $-0.050^{* * *}$ \\
\hline & $(0.0579)$ & $(0.012)$ & $(0.008)$ \\
\hline \multirow[t]{2}{*}{$M B_{i, t}$} & $0.207^{\star * *}$ & $0.018^{\star *}$ & 0.008 \\
\hline & $(0.041)$ & $(0.008)$ & $(0.005)$ \\
\hline \multirow[t]{2}{*}{$N_{C S K E W_{i, t}}$} & $0.294^{\star * *}$ & $0.066^{* * *}$ & $0.047^{\star * *}$ \\
\hline & $(0.056)$ & $(0.013)$ & $(0.008)$ \\
\hline \multirow[t]{2}{*}{ Opaque $_{i, t}$} & -0.416 & $0.324^{*}$ & 0.114 \\
\hline & $(0.959)$ & $(0.178)$ & $(0.122)$ \\
\hline \multirow[t]{2}{*}{ Inshold $_{i, t}$} & $1.262^{* * *}$ & $0.087^{* *}$ & 0.043 \\
\hline & $(0.228)$ & $(0.042)$ & $(0.028)$ \\
\hline \multirow[t]{2}{*}{$L E V_{i, t}$} & -0.166 & -0.033 & -0.018 \\
\hline & $(0.289)$ & $(0.056)$ & $(0.038)$ \\
\hline \multirow[t]{2}{*}{$R O A_{t, t}$} & $21.069^{* * *}$ & 0.154 & 0.019 \\
\hline & $(1.112)$ & $(0.221)$ & $(0.147)$ \\
\hline \multirow[t]{2}{*}{ Top10 $0_{i, t}$} & $0.006^{*}$ & 0.001 & $0.001^{\star}$ \\
\hline & 0.003 & $(0.001)$ & $(0.000)$ \\
\hline Industry fixed effect & Control & Control & Control \\
\hline Year fixed effect & Control & Control & Control \\
\hline Observations & 9925 & 9925 & 9925 \\
\hline R-squared & 0.826 & 0.060 & 0.061 \\
\hline
\end{tabular}


Table 6. Endogenous concern for the impact of different analysts coverage and crash risk. The first and second column show the first stage regression result, and the third and fourth column is the regression result in second stage. All variables are as defined in Appendix A. The standard errors are reported in parentheses. The superscripts ${ }^{*},{ }^{* *}$, and ${ }^{* * *}$ indicate statistical significance at the $10 \%, 5 \%$ and $1 \%$ levels, respectively.

\begin{tabular}{|c|c|c|c|c|}
\hline \multirow{2}{*}{ VARIABLES } & \multicolumn{2}{|c|}{ First stage } & \multicolumn{2}{|c|}{ Second stage } \\
\hline & Star $_{i, t}$ & nonStar $_{i, t}$ & $N C S K E W_{i, t+1}$ & $D U V O L_{i, t+1}$ \\
\hline \multirow[t]{2}{*}{ Constant } & $-5.674^{* * *}$ & $-9.696^{* * *}$ & $0.474^{*}$ & $0.718^{* * *}$ \\
\hline & $(0.489)$ & $(1.053)$ & $(0.261)$ & $(0.178)$ \\
\hline \multirow[t]{2}{*}{ exp_star ${ }_{i, t}$} & $0.443^{\star * *}$ & $0.485^{\star * *}$ & & \\
\hline & $(0.013)$ & $(0.026)$ & & \\
\hline \multirow[t]{2}{*}{ exp_nonstar $r_{i, t}$} & $0.166^{\star * *}$ & $0.920^{* * *}$ & & \\
\hline & $(0.005)$ & $(0.011)$ & & \\
\hline \multirow[t]{2}{*}{ Star $_{i, t}$} & & & $-0.044^{\star * *}$ & $-0.031^{\star * *}$ \\
\hline & & & $(0.015)$ & $(0.010)$ \\
\hline \multirow[t]{2}{*}{ nonStar $_{i, t}$} & & & $0.023^{\star * *}$ & $0.016^{* * *}$ \\
\hline & & & $(0.005)$ & $(0.003)$ \\
\hline \multirow[t]{2}{*}{$R E T_{i, t}$} & -2.397 & $-63.879^{* * *}$ & 3.714 & 3.714 \\
\hline & $(12.062)$ & $(22.413)$ & $(6.032)$ & $(4.109)$ \\
\hline \multirow{2}{*}{$\operatorname{SIGMA}_{i, t}$} & $12.997^{* * *}$ & $25.683^{\star * *}$ & $3.349^{* * *}$ & $1.842^{* * *}$ \\
\hline & $(1.178)$ & $(2.433)$ & $(0.620)$ & $(0.422)$ \\
\hline \multirow[t]{2}{*}{$D T U R N_{i, t}$} & $-0.132^{\star *}$ & -0.113 & -0.018 & -0.000 \\
\hline & $(0.061)$ & $(0.125)$ & $(0.033)$ & $(0.023)$ \\
\hline \multirow{2}{*}{$S I Z E_{i, t}$} & $0.209^{* * *}$ & $0.497^{* * *}$ & $-0.045^{* * *}$ & $-0.047^{\star * *}$ \\
\hline & $(0.022)$ & $(0.048)$ & $(0.012)$ & $(0.008)$ \\
\hline \multirow[t]{2}{*}{$M B_{i, t}$} & 0.012 & $0.184^{\star * *}$ & $0.015^{\star *}$ & 0.006 \\
\hline & $(0.015)$ & $(0.034)$ & $(0.008)$ & $(0.005)$ \\
\hline \multirow[t]{2}{*}{$N C S K E W_{i, t}$} & $0.106^{* * *}$ & $0.187^{\star * *}$ & $0.068^{* * *}$ & $0.048^{* * *}$ \\
\hline & $(0.023)$ & $(0.047)$ & $(0.013)$ & $(0.008)$ \\
\hline \multirow{2}{*}{ Opaque $_{i, t}$} & 0.361 & -0.645 & $0.354^{* *}$ & 0.135 \\
\hline & $(0.374)$ & $(0.780)$ & $(0.177)$ & $(0.122)$ \\
\hline \multirow[t]{2}{*}{ Inshold $_{i, t}$} & $0.217^{\star *}$ & $1.032^{\star * *}$ & $0.081^{*}$ & 0.039 \\
\hline & $(0.083)$ & $(0.186)$ & $(0.042)$ & $(0.028)$ \\
\hline \multirow[t]{2}{*}{$L E V_{i, t}$} & 0.063 & -0.269 & -0.024 & -0.012 \\
\hline & $(0.104)$ & $(0.238)$ & $(0.057)$ & $(0.038)$ \\
\hline \multirow[t]{2}{*}{$R O A_{t, t}$} & $5.978^{* *}$ & $14.878^{\star * *}$ & 0.254 & 0.088 \\
\hline & $(0.423)$ & $(0.911)$ & $(0.223)$ & $(0.149)$ \\
\hline \multirow[t]{2}{*}{ Top $10_{i, t}$} & $0.002^{*}$ & 0.004 & 0.001 & $0.001^{*}$ \\
\hline & $(0.001)$ & $(0.002)$ & $(0.001)$ & $(0.000)$ \\
\hline Industry fixed effect & Control & Control & Control & Control \\
\hline Year fixed effect & Control & Control & Control & Control \\
\hline Observations & 9925 & 9925 & 9925 & 9925 \\
\hline $\mathrm{R}$-squared & 0.634 & 0.805 & 0.056 & 0.058 \\
\hline
\end{tabular}




\subsubsection{Star Analyst, Non-Star Analyst and Crash Risk}

To solve the potential endogeneity problem, similar using the expected star analyst coverage and expected non-star analyst coverage, denoted as exp_star and exp_nonstar, as an instrumental variable to estimate the relation between analyst coverage and crash risk. To calculate the expected analyst coverage, firstly, use Equation (10) and Equation (11) to estimate the exp_star and exp_nonstar

$$
\begin{gathered}
\text { Expected Anal }_{i, j, t}=\frac{\text { Brokersize }_{j, t}}{\text { Brokersize }_{j, t-1}} * \text { Anal }_{i, j, t-1} \\
\text { exp_anal } \\
=\sum_{j, t} \text { Expected Anal }_{i, j, t}
\end{gathered}
$$

where Expected Anal $_{i, j, t}$ is the expected star analysts or expected non-star analysts in broker $j$ in firm $i$ on year $t$. Brokersize $e_{j, t}$ and Brokersize $_{j, t-1}$ is a proxy of broker size in broker $j$ on year $t$, which is defined by the total number of analysts employed in broker $j$ on year $t . A A_{i, j, t-1}$ is the star analyst coverage or non-star analyst coverage for broker $j$ s coverage of firm $i$ on year $t-1$. exp_anal ${ }_{i, t}$ represent exp_star and exp_nonstar.

I use the 2 sls regression to estimate Equation (5), the result showing in Table 6. The result shows that the coefficient of Star is negative and the coefficient of nonstar is positive, supporting hypothesis $\mathrm{H} 2$.

\section{Conclusion}

This paper estimates the relationship between analyst coverage and stock price crash risk depending the sample on 2010 to 2016 in China stock market. The study finds that, on average, the supervision role of analysts is weaker, so the following of analysts cannot decrease the crash risk. Much worse is that the following of analysts increases the crash risk. The finding shows that the systematic positive deviation dominated the impact of analyst coverage to crash risk, which exacerbated the accumulation of bad news. Furthermore, I divide the security analysts into star analysts and non-star analysts based on the New Fortune magazine. The study shows that the star analyst coverage can decrease crash risk, but the coverage of non-star analysts increases the crash risk. The finding shows that the star analyst may act as an effective external supervision, which reduces managers' opportunism activities. Also, with the relative raise of star analysts, it may have a lower crash risk. Compared to the non-star analysts, the star analysts are more professional, which means more accurate forecast. Meanwhile, the reputation mechanism may constrain their misconduct activity. Thus the finding also shows that it is essential to improve the profession of analysts. And the reputation mechanism is really effective.

\section{References}

[1] Yu, F. (2008) Analyst Coverage and Earnings Management. Journal of Financial Economics, 88, 245-271. https://doi.org/10.1016/j.jfineco.2007.05.008

[2] Hong, Y., Huseynov, F. and Zhang, W. (2014) Earnings Management and Analyst Following: A Simultaneous Equations Analysis. Financial Management, 43, 355-390. 
https://doi.org/10.1111/fima.12043

[3] Myers, S.C. and Jin, L. (2006) R-Squared Around the World: New Theory and New Tests. Journal of Financial Economics, 79, 257-292. https://doi.org/10.1016/j.jfineco.2004.11.003

[4] Xu, N., Jiang, X., Chan, K.C., et al. (2013) Analyst Coverage, Optimism, and Stock Price Crash Risk: Evidence from China. Pacific-Basin Finance Journal, 25, 217-239. https://doi.org/10.1016/j.pacfin.2013.09.001

[5] Hutton, A.P., Marcus, A.J. and Tehranian, H. (2009) Opaque Financial Reports, R2, and Crash Risk. Journal of Financial Economics, 94, 67-86.

https://doi.org/10.1016/j.jfineco.2008.10.003

[6] Kothari, S.P., Shu, S. and Wysocki, P.D. (2009) Do Managers Withhold Bad News? Journal of Accounting Research, 47, 241-276.

https://doi.org/10.1111/j.1475-679X.2008.00318.x

[7] Kim, J.B., Li, Y. and Zhang, L. (2011) CFOs versus CEOs: Equity Incentives and Crashes. Journal of Financial Economics, 101, 713-730. https://doi.org/10.1016/j.jfineco.2011.03.013

[8] Benmelech, E., Kandel, E. and Veronesi, P. (2010) Stock-Based Compensation and CEO (Dis)Incentives. Quarterly Journal of Economics, 125, 1769-1820. https://doi.org/10.1162/qjec.2010.125.4.1769

[9] Kim, J.B. and Zhang, L. (2010) Does Accounting Conservatism and Stock Price Crash Risk: Firm-Level Evidence. Working Paper, City University of Hong Kong.

[10] Wang, H.C., Cao, F., Gao, S.H., et al. (2014) Investor Protection and Stock Price Crash Risk. Finance \& Trade Economics, 35, 73-82.

[11] Wang, H.C., Cao, F. and Ye, K.T. (2015) Monitoring or Tunneling? The Proportion of the Proportion Held by the Big Shareholders and the Risk of the Crash of the Stock Price. Management World, No. 2, 45-57.

[12] Wan, D.C. (2015) Audit Fees and Risk of Stock Price Crash. Auditing Research, No. 6, 85-93.

[13] An, H. and Zhang, T. (2013) Stock Price Synchronicity, Crash Risk, and Institutional Investors. Journal of Corporate Finance, 21, 1-15. https://doi.org/10.1016/j.jcorpfin.2013.01.001

[14] Barth, M.E. and Hutton, A.P. (2000) Information Intermediaries and the Pricing of Accruals. Working Paper, Stanford University, Stanford, CA.

[15] Matsunaga, S.R. and Park, C.W. (2001) The Effect of Missing a Quarterly Earnings Benchmark on the CEO's Annual Bonus. Accounting Review, 76, 313-332. https://doi.org/10.2308/accr.2001.76.3.313

[16] Jensen, M.C. (2010) Agency Costs of Overvalued Equity. Financial Management, 34, 5-19. https://doi.org/10.1111/j.1755-053X.2005.tb00090.x

[17] Degeorge, F., Ding, Y., Jeanjean, T., et al. (2013) Analyst Coverage, Earnings Management and Financial Development: An International Study. Journal of Accounting \& Public Policy, 32, 1-25. https://doi.org/10.1016/j.jaccpubpol.2012.10.003

[18] Li, C.T., Zhao, Y., Xu, X., et al. (2016) Discourage One to Encourage Another: Analysts Following and Corporate Earnings Management Strategy. Journal of Financial Research, No. 4, 144-157.

[19] Xu, N., Chan, K.C., Jiang, X., et al. (2013) Do Star Analysts Know More Firm-Specific Information? Evidence from China. Journal of Banking \& Finance, 37, 89-102. https://doi.org/10.1016/j.jbankfin.2012.08.014

[20] Wu, Y.R., Pan, K., Hu, S.M., et al. (2012) A New Explanation of Industry Analyst 
Earnings Forecast Bias. Economic Research Journal, No. 4, 149-160.

[21] Pan, Y., Dai, Y.Y. and Liu, S.C. (2011) Do Underwriters Provide Price Support by Analyst Coverage in China? Economic Research Journal, No. 3, 131-144.

[22] Zhao, L.Y., Li, Z.Q. and Liu, J.X. (2013) The Managers' Preferences, the Optimization in the Evaluation of the Investment Level and the Obtainment of the Private Information. Management World, No. 4, 33-47.

[23] Xu, N.H., Jiang, X.Y., Yi, Z.H., et al. (2012) Conflicts of Interest, Analyst Optimism and Stock Price Crash Risk. Economic Research Journal, No. 7, 127-140.

[24] Pan, Y., Dai, Y.Y. and Lin, C.Q. (2011) Information Opacity, Analysts Following and Crash Risk. Journal of Financial Research, No. 9, 138-151.

[25] Xiao, H. and Li, S.-X. (2017) The Effect of Other Comprehensive Income Reporting on Analyst Forecasts-From the Perspective of the Characteristics of Enterprise Accounting Information Environment and the Cognitive Ability of Analysts. Journal of Shanxi University of Finance and Economics, No. 12, 100-113.

[26] Li, Y., Wang, L. and Wang, M.C. (2015) Are Star Analysts' Recommendation More Profitable?-The Evidence from Media Coverage. Review of Investment Studies, No. 5, 143-160.

[27] Wu, C.P., Zheng, F.B. and Yang, S.J. (2013) Are Analysts' Earnings Forecasts and Investment Recommendations Objective? China Economic Quarterly, 12, 935-958.

[28] Zhang, Z.X. and Yao, P.Y. (2018) Novelty, Risk Averse, or Striving for Perfection?-The Evidence from the Inclination of Star Analysts' Estimates. Securities Market Herald, No. 1, 46-53.

[29] Lin, J., Zhou, M.-S. and Dong, Z.-Y. (2017) Does Security Law Enforcement Strengthen Analysts' Role as External Monitors. Journal of Shanxi University of Finance and Economics, No. 3, 97-110.

[30] Hu, F. and Xia, Y. (2017) Analysts' Commercial Motivations and Earnings Forecast Bias: Evidence from Margin Transactions. Journal of Finance and Economics, 43, 45-56.

[31] Li, D., Yuan, C. and Liao, G.M. (2016) Short Selling and Analyst Optimistic Bias-Based on DID Model. Accounting Research, No. 9, 25-31.

[32] Dechow, P.M., Sloan, R.G. and Sweeney, A.P. (1995) Detecting Earnings Management. Accounting Review, 70, 193-225.

[33] Zhou, M.S., Lin, J. and Xu, N.H. (2016) Star Analyst Coverage and Stock Price Synchronicity: Empirical Evidence Based on Market Overreaction. Journal of Management Sciences in China, 19, 49-73. 


\section{Appendix A}

\begin{tabular}{|c|c|}
\hline \multicolumn{2}{|r|}{ A. Dependent variables } \\
\hline$N C S K E W_{i, t+1}$ & $N C S K E W$ is the negative coefficient of skewness. See Equation (2) for detail \\
\hline$D U V O L_{i, t+1}$ & $D U V O L$ is the down-to-up volatility. See Equation (3) for detail \\
\hline \multicolumn{2}{|r|}{ B. Independent variables } \\
\hline Coverage $_{i, t}$ & Number of analysts who issued earnings for cast for a firm in fiscal year \\
\hline Star $_{i, t}$ & $\begin{array}{l}\text { Number of star analysts for firm } i \text { in year } t \text {. If an analyst is selected by New } \\
\text { Fortune magazine as the best analyst in year } t-1 \text {, he or she is considered as } \\
\text { a star analyst in year } t \text {. }\end{array}$ \\
\hline nonStar $_{i, t}$ & $\begin{array}{l}\text { Number of non-star analysts for firm } i \text { in year } t \text {. } \\
\text { It is the difference between Coverage and Star }\end{array}$ \\
\hline Ratio $_{i, t}$ & The ratio between Star and Coverage \\
\hline \multicolumn{2}{|r|}{ C. Control variables } \\
\hline$N C S K E W_{i, t}$ & The lagged value of $N C S K E W$ \\
\hline$R E T_{i, t}$ & $R E T$ is the mean of firm-specific weekly returns in year $\mathrm{t}$ \\
\hline SIGMA & $S I G M A$ is the standard deviation of firm-specific returns in year $t$ \\
\hline$L E V_{i, t}$ & $L E V$ is the book value of all liabilities scaled by the book value of assets. \\
\hline$M B_{i, t}$ & $M B$ is the market-to-book ratio \\
\hline$S I Z E_{i, t}$ & SIZE is the log of firm's total assets \\
\hline$D T U R N_{i, t}$ & $\begin{array}{l}D T U R N \text { is the average monthly share turnover for } t \text { year minus the average } \\
\text { monthly share turnover for } t-1 \text { year. }\end{array}$ \\
\hline$R O A_{1, t}$ & $R O A$ is income divided by total assets \\
\hline Inshold $_{i, t}$ & Inshold is the shareholding of institution investor \\
\hline Top $10_{i, t}$ & Top 10 is the shareholding of top 10 shareholder \\
\hline Opaque $_{i, t}$ & $\begin{array}{l}\text { Opaque represent the information opaque in year } t \text {. Firstly, estimate the } \\
\text { discretionary accurals, denote } D A \text {, using modified Jones model (Dechow et } \\
\text { al. 1995) [32]. Then use Equation (12) to estimate Opaque. } \\
\text { Opaque }_{i, t}=\frac{a b s\left(D A_{t, t}\right)+a b s\left(D A_{t, t-1}\right)+a b s\left(D A_{t, t-2}\right)}{3}\end{array}$ \\
\hline exp_cov ${ }_{i, t}$ & $\begin{array}{l}\text { Expected analyst coverage if firm } i \text { in year } t \text {. See } \\
\text { Equation (8) and Equation (9) for detail }\end{array}$ \\
\hline exp_star ${ }_{i, t}$ & $\begin{array}{l}\text { Expected star analyst coverage if firm } i \text { in year } t \text {. See } \\
\text { Equation (10) and Equation (11) for detail }\end{array}$ \\
\hline exp_nonstar $r_{i, t}$ & $\begin{array}{l}\text { Expected non-star analyst coverage if firm } i \text { in year } t \text {. See } \\
\text { Equation (10) and Equation (11) for detail }\end{array}$ \\
\hline
\end{tabular}

